Article

\title{
Design Mode Innovation of Local Color Cultures: A Case Study of the Traditional Female Costume of Yi Nationality
}

\author{
Zhe Ji ${ }^{1, *}$, Wei-Hsin Huang ${ }^{2}$ and Mengyi Lin ${ }^{1}$ \\ 1 The Graduate Institute of Design Science, Tatung University, Taipei 104, Taiwan; d10517014@ms.ttu.edu.tw \\ 2 Department of Media Design, Tatung University, Taipei 104, Taiwan; wshuang@gm.ttu.edu.tw \\ * Correspondence: d10517015@ms.ttu.edu.tw; Tel.: +86-135-9990-7331
}

Received: 20 November 2020; Accepted: 15 December 2020; Published: 17 December 2020

\begin{abstract}
Color is a concrete expression of combining local features and traditional culture. The purpose of this study is to provide a new design method and intends, by taking the traditional costume of the Yi women in Liangshan, China, as an example, to establish a systematic color scheme which can be used as a reference for the establishment of relevant color records for other cultural groups. First of all, through literature review, this study provides the definition of the traditional costume of the Yi women in Liangshan, color and culture and color images and clarifies the characteristics of research samples. Secondly, experts are invited to find out and record the color values of different colors on Yi women's costume, and a software is resorted to in order to calculate the area ration of each color and analyze the color distribution principles of sample costume. Moreover, this study discusses the color images of Yi women's costume, sorts out its unique color characteristics and establishes and verifies samples of color scheme through focus group interviews in order to analyze regional cultural colors. Finally, this study proposes a systematic approach for regional cultural color analysis, namely, understanding color characteristics, analyzing color images, establishing a color scheme and demonstrating color scheme principles. Through a systematic approach, these cultural colors are analyzed and organized to establish a regional cultural color scheme, which can not only retain the characteristics of the traditional cultural colors of Chinese ethnic groups' costume but also serve as a reference for designers to develop regional cultural products.
\end{abstract}

Keywords: Liangshan Yi; geography of color; color scheme; color images

\section{Introduction}

In October 2005, UNESCO (United Nations Educational, Scientific and Cultural Organization) formally adopted "the Convention on the Protection and Promotion of the Diversity of Cultural Expressions" [1], which mentioned the protection of the cultural diversity of various regions and countries, encouraged intercultural communication and encouraged countries to use culture Policies and cultural industries to promote and prosper the diversity of culture, that is, to protect the "cultural ecology" that exists in a diversified manner on which humanity depends. Cultural diversity enriches human life and is the product of human wisdom. The rise of cultural and creative industries is a driving force that promotes national economic growth and industrial upgrading. Due to the globalized mainstream culture of powerful state, the uniqueness of the minority culture is gradually disappearing. In such condition, it is necessary to protect and preserve the unique culture of each ethnic group.

China is a multi-ethnic country. With a population of about 8.71 million, the Yi people mainly live in southwestern China in places such as Sichuan, Yunnan and Guizhou. It is the sixth largest ethnic minority in China. "The clothing system of the Yi people can be geographically divided into Chuxiong 
type, Liangshan type, Wumengshan type, western Yunnan type, Honghe type, Dianchi type and southeastern Yunnan type" [2]. Among them, Liangshan type is the most colorful and representative one among all the Yi women's costume.

Ethnic costume is an important symbol of ethnic characteristics and contains profound connotations of local culture and traditions. The preference for different colors shows the differences in beliefs of various ethnic groups. In recent years, economic opening up and the rapid development of regional economy have diluted ethnical culture. The integration of the traditional Yi culture with the mainstream culture has changed the color scheme of traditional costume, and it is possible to lose the integrity of Yi costume as a result of cultural blending if not properly recorded and preserved. In recent years, scholars have discussed the national costume and color. Ning Sun discussed the main content of national costume elements and the meaning of its application to modern costume design [3]. Xiao-ran Feng studied the influence of national style costume on the way of people's dressing and the application of national elements such as national costume color, pattern, decoration and handmade art in modern fashion design [4]. Bakieva, O.A. and Popova, O.A., studied the color symbolism in the costume through ethno-psychology, which allows to make sure that the color mentality of the few indigenous Northern ethnic groups of the Khanty is correct [5]. Juan Li discussed shapes of traditional Chinese border by analyzing historical costume materials, summing up the characteristics of Chinese border in ornament from colors and patterns [6].

The specific expression of color combines regional features and traditional culture. In 1989, French colorist Philippe Lenclos proposed the geography of color [7]. This method is a systematic way to investigate nature and human society from the perspective of color. Through investigation, records of color measurement, evidence obtaining, induction, genealogizing, color uniqueness genealogizing and other practical methods, the research objects are categorized according to main colors, decorative colors and color schemes, so as to preserve the regional cultural colors and understand color characteristics based on geographical features, ethnic distribution, history and culture. With the development of research on ethnic culture, integrating ethnic culture into designing has become an important part in the design of cultural and creative products in China today. The purpose of this study is to provide a new design method. At present, there is no color scheme that is inspired by Chinese geography and culture. Therefore, this study intends to take the traditional female costume of Yi people as the research object and build a color scheme which is in accordance with ethnical and regional culture through observation, evidence sorting, induction and analysis, so as to preserve the traditional characteristics of regional cultural colors and serve as a reference for designers to develop products related to ethnical culture.

\section{Literature Review}

\subsection{Color and Culture}

Color is light, carried on wavelengths, which are absorbed by the eyes and are converted by the brain into the colors that we see [8]. When an object is exposed to light, wavelengths that are not absorbed are reflected into human eyes to present the color of the object. Due to the difference in wavelength, there are many colors such as red, orange, yellow, green, blue and purple. Color has three attributes, namely hue, value and chroma [9]. Hue is the appearance of the color, value is the degree of lightness and darkness of the color, and chroma is the degree of brightness of the color.

By putting more than two colors together, a new visual effect is produced, and it is called "color scheme". Tsuneo Kondou divided the components of color scheme into four types: primary color, secondary color, accent color and decorative color [10]. Although color scheme can be different according to personal preference, fashion of the time or geographical environment, several principles can be summarized for optimized color scheme. The six basic principles of color scheme are balance, emphasis, contrast, rhythm, dominant color and separation. Many researchers have suggested that color directly affects the parts of a human's nervous system that are responsible for the arousal of emotions, and different colors or color combinations usually have different meanings for people [11]. 
As color emotion is in the domain of psychology, it is influenced by many factors, such as sex, age, climate and geographic conditions, as well as race and cultural influences [11]. Color connotation and symbolic meanings are rich in Chinese culture, and the meaning of words about color can be diverse. For example, red is the most commonly used color in Chinese classical culture, and it reflects the Chinese people's pursuit in many aspects, both spiritually and materially. It symbolizes auspicious, festive, prosperous, smooth and successful things. For example, red lanterns and red couplets are hung on special festive days, and men and women wear red on their wedding. Yellow is a continuation and development of red color in Chinese culture. It also represents power, majesty and the central government and is a color exclusively used by emperors in the past. The white color in Western culture has different symbolic meaning from that in the East. Westerners believe that white is elegant and pure, which symbolizes innocent and pure mind, integrity and honesty, such as the bride's white wedding dress.

With the development of economy, in order to attract consumers, designing distinctive products with market competitiveness is the goal of many manufacturers. Colors can have powerful psychological effects and evoke emotions; therefore, they change our behavior too, which is also supported by science, as color addresses one of our basic neurological needs for stimulation [12]. For consumers, visual appearance and color are placed above other factors when shopping (1\% sound/smell, $6 \%$ texture, and $93 \%$ visual appearance) [13]. Consumers make up their minds within $90 \mathrm{~s}$ of their initial interactions with either people or products, and about $62 \% \sim 90 \%$ of the assessment is based on colors alone [8]. For retailers, shopping is the art of persuasion. While there are many factors that influence how and what consumers buy, $85 \%$ of shoppers consider color to be the primary reason for why they buy a particular product [13]. Therefore, the use of color has become one of the most efficient elements in design. Color selection and application are very important abilities for designers, while color scheme is a very important reference for designers in color application. This study employs Yi women's traditional costume as a sample for research on colors, analyzes the uniqueness generated from color scheme and establishes the principle of regional cultural color scheme as the basis for the application of regional cultural colors in the future.

\subsection{Female Costume of Liangshan Yi}

The basic components of costume include color, pattern and shape and material. Generally speaking, when people look at an object, they first notice its color, then the shape, and last, they recognize the material and texture of the object by close observation. Therefore, color can be considered as the most striking feature of the appearance of an object. In ancient times, culture was formed through the accumulation of life experience, and costume is a demonstration of social and cultural preservation. Costume is a social behavior of human beings in order to maintain management and change their appearance, and it also refers to any objects or behaviors that aim to change the appearance of human bodies [14].

Ethnic color is an important part of the intangible cultural heritage of ethnic minorities. By analyzing the use of color by ethnic minorities, we can understand the unique aesthetic methods and tastes of ethnic culture. The color culture of Yi people's costume has a history of more than 3000 years. Black, red and yellow are the three distinctive colors of Yi people's costume in Liangshan, forming a "three-color culture" with unique Yi characteristics [15]. Through imagination and creation, they subtly combine these three colors with different patterns to create beautiful and unique costume.

In Nuosu language of Liangshan, black means deep, heavy, high, large and dense. “The Yi people's admiration for black was originated from the worship of land, using black to symbolize the nobility of class and lineage. The Yi people favor black, one of the historical title related to Yi people is called "dong cuan wu man" (wu means the black color in Chinese), and their names of self-identification such as "nuo su", "nuo su" and "ni su" are also related to the black color ("nuo", "nuo" and "ni" means black in Chinese) [16]. Moreover, the Yi people refer dark colors such as cyan and blue as "na", meaning black, which further expands the semantic coverage of "black" [17]. Red represents life and 
passion in the beliefs of the Yi people. They believe that red can avoid evil and bring people the ability to regenerate. The worship of yellow among the Yi people comes from their ancestors' worship of the sun, and yellow represents vitality, hope, harvest and eternity.

Traditional Yi costume is rich in decorative elements. The hard-working and intelligent Yi women have discovered beautiful graphics and colors from the nature, the process of production and life, and apply abstract thinking to the design and production of costume. The decorative patterns are designed elaborately, the color scheme is simple and bright, and the overall tone is calm and harmonious. Through Yi women's hand-made products, distinctive ethnic characteristics are thus presented. Yi women in Liangshan usually wear skirts and headbands, and they change to hats or head wrappings after giving birth. Their garments have buttons on the right with three types including shirts, overcoats and vests decorated with thin strips in flower shape, applique and embroidery and red, yellow and green pinstripes. Their pleated long skirts for adults are divided into three or four sections, each with different colors. The upper section is the waist part, the middle section is straight, and the lower section is wrinkled. When walking, the hemline of the skirt swings with the pace, making the woman wearing it more graceful and attractive. Their garments are matched with portable triangular purses, which are embroidered with various patterns and decorated with five-color streamers at the bottom [18]. The main colors of women's costume are black, blue and cyan, accompanied with red, yellow, green and pink patterns, featuring strong contrast between colors and clear rhythms.

The perception of color is in the brain of the observer, and the colors we know are the product of our language and culture [19]. Applying the color scheme of the Yi people to design conveys the symbolic meaning of the Chinese regional culture by transforming the design of traditional cultural colors through a brand-new perspective. Through transforming the aesthetic elements in history, the traditional culture is passed on, and the user's feelings and cognitive consciousness are connected. This study employs the color scheme of Yi women's costume as the medium for design transformation, and the resources of cultural colors of Yi people are developed and converted into cultural capital through researching on regional cultural colors and graphics, which attaches historical and practical significance to the promotion of the development and tourism products of Yi culture.

\subsection{Visual Images}

Color is the perception of light by human eyes. When the light stimulates the visual nerves on the retina, it causes a series of perceptual reactions, thereby human can perceive the existence of color. When people see a color, in addition to physical feeling, psychology feeling is also produced. Such psychological feeling caused by color is the so-called color image in this study.

As Zhang Chunxing mentioned in "Zhang's Dictionary of Psychology", image is the reappearance of past experience in memory. In "Concise Dictionary of Psychology", image is a mixture of ideas, judgments, preferences and attitudes towards a wide range of things, which emphasizes the content of cognition in terms of mood and feeling. The scholar McKellar pointed out that $97 \%$ of people can feel the image through visual stimulation, $93 \%$ through auditory stimulation, and $76 \%$ through tactile stimulation. Among relevant research and studies, most are about visual image, because the appearance of objects is directly related to human feelings, and humans can easily build psychological associations through external influences [20]. Philip G. Zimbardo mentioned in "Psychology and Life" that human's perception process can be divided into three stages: sensation, perception and categorization. External stimulation first causes sensation and then perception, which is a process started from physical stimulation and then transformed to be psychologically meaningful. In this series of studies, the overall goal is to clarify the relationship between color emotion and color preference.

At present, the main method used in the study of "image" is Method of Semantic Differential advocated by Osgood [21], which refers to the use of adjectives as a measurement to study the "meaning" of things or concepts. Method of Semantic Differential is widely adopted as an effective method for identifying product images. 
In 1966, Kobayashi founded Nippon Color and Design Research Institute to conduct research on color, design and consumer preferences from the perspective of psychology. As a leader in the field of color psychology, the Method of Semantic Differential developed by him obtained a patent for image plan, and he also developed a perceptual database and program of color scheme on computer. Kobayashi, in his "color image scale" study, developed three main dimensions of color emotions: warm-cool, soft-hard and clear-greyish [22].

It was also shown, however, that color preference can be influenced by a variety of factors such as cultural context [23-25], age [26], gender [25,27], design training [23-26] and individual experiences [28]. Li-Chen Ou classifies color emotions for single colors and develops color-science-based color emotion models. The results show that for each color emotion the models of the three studies agreed with each other, suggesting that the four color emotions are culture-independent across countries [29]. In 2002, Mingzhen Zhuang, a Taiwan scholar, explored the cognitive differences in color images based on personal factors. Method of Semantic Differential was adopted to figure out the image perception of 138 subjects on color samples. Five factors were derived from 22 sets of adjectives. Then, each subject's perception of color image was marked in space coordinate and categorized according to personalities. The results showed that gender has the greatest impact on the perception of color images, personalities also have a slight impact, while constellation and blood type have little effect.

Through literature review above, it can be concluded that image-related research mostly employs Method of Semantic Differential, converts psychological feelings into numbers through certain measurement and analyzes them. This study analyzes the color images of Yi women's costume through Method of Semantic Differential and statistical tools in order to figure out the image that the sample costume brings to the subject.

\section{Methods}

This study takes the traditional costume of Yi women in Liangshan, China as an example to analyze regional cultural colors (Figure 1). First of all, through a literature review, this study provides the definition of the traditional costume of the Yi women in Liangshan, color and culture, and color images and clarifies the characteristics of research samples. Secondly, colors of the samples are recorded with numerical values and calculated by a software to find out the proportion of each color, thus analyzing the color distribution principles of the sample costume. In addition, questionnaires based on Method of Semantic Differential are resorted to to explore the color images of samples and compile the principles of color scheme. At last, this study establishes and verifies the samples of color scheme through focus group interviews in order to analyze regional cultural colors.

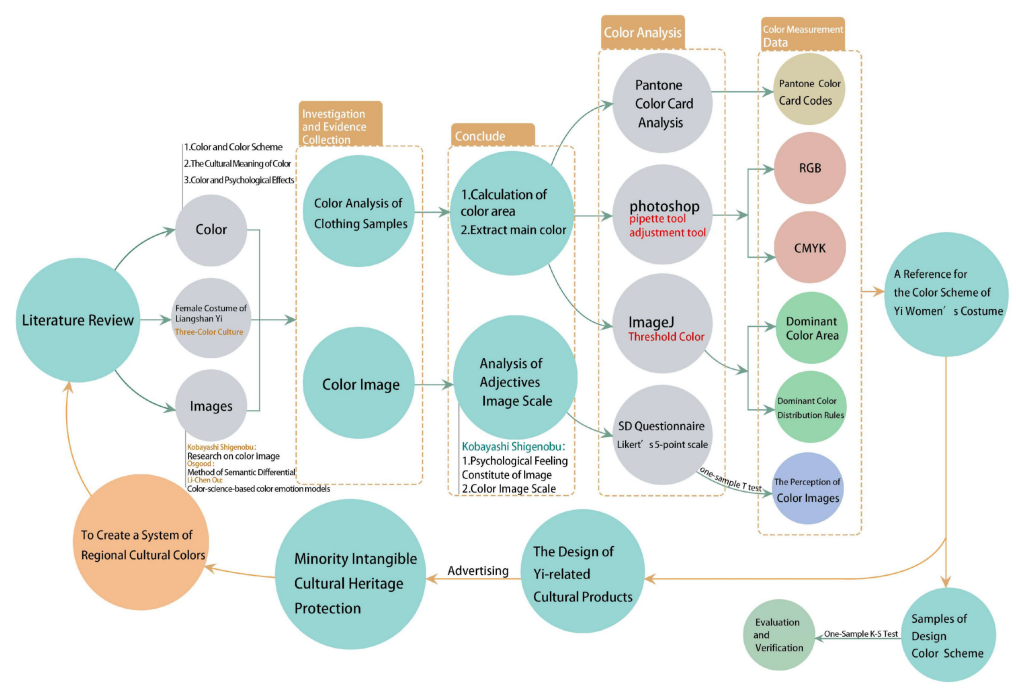

Figure 1. Research framework. 


\subsection{Data Collection}

This study consists of four parts: color analysis, color images, color scheme design and color scheme verification.

\subsubsection{Color Analysis}

In this study, color analysis is performed through Pantone Color Guide and ImageJ (Figure 2). Firstly, Pantone Fashion Home + Interiors Color Guide (FHI Color Guide) is employed, which includes 2625 FHI colors. Pantone Color Guide is currently widely used in printing and fabrics, whose color code are listed in the order of lightness, hue, and saturation. After a certain color is selected, its color code will be converted into RGB (color model) or CMYK (color model) values by Photoshop for color analysis. Photoshop calculates the RGB and CMYK values of Pantone Color Guide by pipette tool and adjustment tool. ImageJ is a free image processing software developed by the National Institutes of Health (NIH), which is mainly used in the field of biomedicine, mechanics and chemical engineering. This study adopts Threshold Color (a plug-in concerning the threshold value in ImageJ) to measure the area of each color.

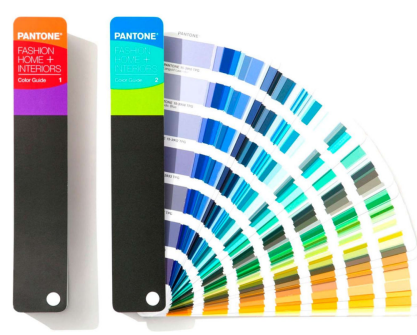

(a)

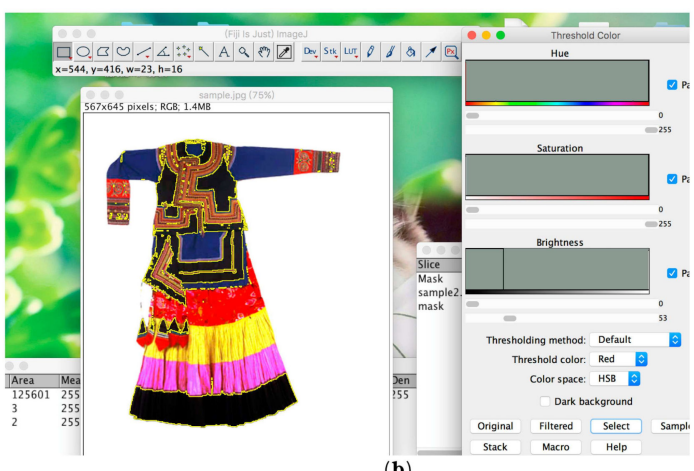

(b)

Figure 2. (a) Pantone color guide. (b) ImageJ.

\subsubsection{Color Images}

Through collecting and analyzing adjectives about the color of Liangshan Yi women's traditional costume, this study finds out the most representative adjectives, edits questionnaires about color images and resorts to SPSS, a statistical tool, for data analysis in order to understand people's feelings about color images of Liangshan Yi women's costume.

\subsubsection{Color Scheme Sample Design}

According to the research content of color analysis and color images, 4 designers with more than 5 years of designing experience are invited to focus group interview to conduct color scheme sample design.

\subsubsection{Color Scheme Sample Verification}

The color scheme sample design is edited into a five-point scale questionnaire, and 30 students with professional experience in design are invited to finish the questionnaire. The results are analyzed through SPSS to verify the applicability of the color scheme sample design.

\subsection{Liangshan $Y i$}

Yunnan and Sichuan are the two provinces with the largest population of Yi nationality. Due to historical, economic and transportation factors, Liangshan Yi Autonomous Prefecture of Sichuan Province has almost completely retained all the original elements of traditional Yi costume. Liangshan Yi women's costume culture is considered the most representative one, and that is the reason why this 
study chooses Liangshan Yi women's costume as the research sample with photographs taken on the spot. In order not to affect the validity of the study, characters and scenes other than female costume are not taken into consideration, nor do headwear, necklaces or other accessories.

\section{Results}

\subsection{Color Analysis}

In order to analyze the colors of Yi women's costume, this study first uses the color threshold function of ImageJ to adjust the value of hue (H), saturation (S), and brightness (B) to a certain color to measure the area of that color. If the color lines of the sample are too thin and close or the colors are not evenly distributed, they will be amended separately in Photoshop and then put in ImageJ to measure the range of a single color and calculate its area ratio. After combining that with the color values obtained through interview with experts, the author summarizes the principles of applying colors on costume with figures and table.

\subsubsection{Color Area Analysis}

The colors of Yi women's costume are composed of 7 colors including blue, black, red, yellow and pink. In terms of the pixel area, ImageJ shows that black is the main color, accounting for $37 \%$ of the total area, blue $14 \%$, red $15 \%$, yellow $15 \%$, pink $12 \%$ and other decorative colors $7 \%$ in total.

\subsubsection{Color Distribution}

The female costume of Yi nationality is mainly black and dark blue. Based on that, it is decorated with bright red and yellow. Using achromatic colors to neutralize chromatic colors makes red and yellow, two wild colors, become quiet and calm yet intense and bright. According to the principle of color harmony among similar colors and adjacent colors, black and dark blue are similar in value and symbolic meaning. Combining black and blue unifies the understanding of these two colors. On the whole, green, orange and pink only account for a small part with low area ratio, so that they do not seem disordered. The top of costume is mainly black and blue, and the lace in yellow, red and orange frequently appears on the cuffs, lapel and hem, forming a strong sense of rhythm and neutralized by the main colors, black and blue. Red, yellow and pink account for a large part of the skirt. The hem of the skirt is in black. Usually, the high-brightness color looks light, and the low-lightness color looks heavy. Placing the high-lightness color above the low-lightness color gives out a sense of stability with light top and heavy bottom, which is in line with the principle of balanced color scheme. The change in color emphasizes the curvaceous beauty of women. After calculating the area ratio of colors and interviewing with experts, the color card codes and color distribution are sorted out, and the results are shown in Table 1.

Table 1. Analysis of the colors on Yi women's costume.

\begin{tabular}{ccccccc}
\hline Color Scheme & Color & $\begin{array}{c}\text { Pixel } \\
\text { Area }\end{array}$ & $\begin{array}{c}\text { Color } \\
\text { Ratio }\end{array}$ & RGB & CMYK & Pantone \\
\hline \multirow{2}{*}{ Dominant Color } & Black & 467,161 & $37 \%$ & $18 / 13 / 2$ & $84 \%, 82 \%, 92 \%, 74 \%$ & $19-4006$ \\
& Red & 188,193 & $15 \%$ & $226 / 4 / 0$ & $13 \%, 93 \%, 100 \%, 0 \%$ & $18-1763$ \\
\multirow{2}{*}{ Secondary Colors } & Yellow & 183,223 & $15 \%$ & $255 / 222 / 29$ & $7 \%, 10 \%, 73 \%, 0 \%$ & $13-0858$ \\
& Blue & 171,140 & $14 \%$ & $0 / 56 / 120$ & $91 \%, 86 \%, 21 \%, 0 \%$ & $18-4434$ \\
& Pink & 153,445 & $12 \%$ & $255 / 156 / 210$ & $7 \%, 50 \%, 0 \%, 0 \%$ & $15-2213$ \\
Decorative Colors & Orange & 62,803 & $5 \%$ & $242 / 134 / 39$ & $5 \%, 60 \%, 86 \%, 0 \%$ & $15-1263$ \\
& Green & 30,089 & $2 \%$ & $9 / 140 / 86$ & $82 \%, 31 \%, 82 \%, 0 \%$ & $17-6030$ \\
\hline
\end{tabular}




\subsection{Color Images}

In order to understand the perception of color images of Yi women's costume, this study analyzes the psychological feelings of the subjects through selecting image-related adjectives, editing questionnaires and handing out questionnaires to participants.

\subsubsection{Image Adjectives Collection}

In terms of adjective collection, first of all, this study refers to previous research on costume images, the psychological feeling constitute of image proposed by Japanese color psychologist, Kobayashi Shigenobu 's [30] and color image scale [31], repeated words are deleted, and a word list of 82 adjectives in total are generated. Then, six experts with more than 5 years of experience in fashion design are invited to select appropriate adjectives to describe the color of Yi women's costume. Those which are chosen by more than three times are selected, and those with high similarity are excluded; thus, the list of 8 sets of adjectives is settled.

Among them, eight sets of adjectives, including “Traditiona-Modern" [32,33], "Splendid-Plain [32,34,35]" "Complex-Simple" [36,37], "Heavy-Light" [25], and "Hard-Soft" [29,35,37,38], were drawn from existing studies. Additionally, another three scales with highest frequencies were drawn from the participants' list, namely "Festive-Sorrowful", "Passionate-Indifferent", and "Unique-Common". Based on this list, a semantic differential (SD) questionnaire is edited, of which the results are shown in Table 2.

Table 2. Eight semantic scales of Yi women's costume.

\begin{tabular}{c}
\hline English \\
\hline Traditional-Modern \\
Splendid-Plain \\
Festive-Sorrowful \\
Complex-Simple \\
Heavy-Light \\
Passionate-Indifferent \\
Unique-Common \\
Hard-Soft \\
\hline
\end{tabular}

\subsubsection{Color Image Survey}

In order to understand the perception of color images of Yi women's costume, this study adopts online questionnaire survey and presents the samples as $15 \mathrm{~cm} \times 17 \mathrm{~cm}$ pictures with 300 ppi through the online questionnaire, so that subjects are able to see them clearly and then finish the questionnaire. The subjects are 106 students and teachers in the field of art and design; among them, males account for $45 \%$ and females for $55 \%$. Finally, 103 valid questionnaires are collected. In this study, 8 sets of adjectives are evaluated through Likert's 5-point scale. The two ends of the scale are no feeling and strong feeling, and the results are converted to numbers (1 to 5 ) for analysis for the sake of convenience.

The following paragraph provides details about the color images of Yi women's costume.

The color images of women's costume: Yi women's costume is mainly black, followed by red, yellow, blue and pink, and features many other colorful ornaments. According to one-sample $\mathrm{T}$ test [39] (Table 3), it can be seen that the 8 sets of adjectives about Yi women's costume are of statistical significance, and the means are Traditional $(M=1.76)$, Complex $(M=1.83)$, Festive $(M=1.88)$, Passionate $(M=1.89)$, Heavy $(M=1.90)$, Hard $(M=2.07)$, Unique $(M=2.30)$ and Splendid $(M=2.74)$. Among these images, "Traditional" is the most frequently felt and the strongest one. 
Table 3. Results of one-sample T test of the color image of Yi women's costume.

\begin{tabular}{cccc}
\hline Image Verification & Mean & $t$ & Sig. (2-Tailed) \\
\hline Traditional-Modern & 1.76 & -13.662 & $0.000^{* * *}$ \\
Splendid-Plain & 2.74 & -2.061 & $0.042^{*}$ \\
Festive-Sorrowful & 1.88 & -13.817 & $0.000^{* * *}$ \\
Complex-Simple & 1.83 & -12.176 & $0.000^{* * *}$ \\
Heavy-Light & 1.90 & -12.054 & $0.000^{* * *}$ \\
Passionate-Indifferent & 1.89 & -12.246 & $0.000^{* * *}$ \\
Unique-Common & 2.30 & -5.978 & $0.000^{* * *}$ \\
Hard-Soft & 2.07 & -10.041 & $0.000^{* * *}$ \\
\hline
\end{tabular}

Note: ${ }^{*} p<0.05,{ }^{* *} p<0.01,{ }^{* * *} p<0.001$.

\subsection{Sample Design of Color Scheme}

Based on the color analysis mentioned above, the area ratio calculated by the software, color distribution, color values obtained from the expert interview and the results of the semantic differential questionnaire about color images are integrated and edited into the illustration of the color scheme of Yi women's costume, which includes sample pictures, RGB and CMYK values (Figure 3), color images, color area ratio and instructions for color scheme.

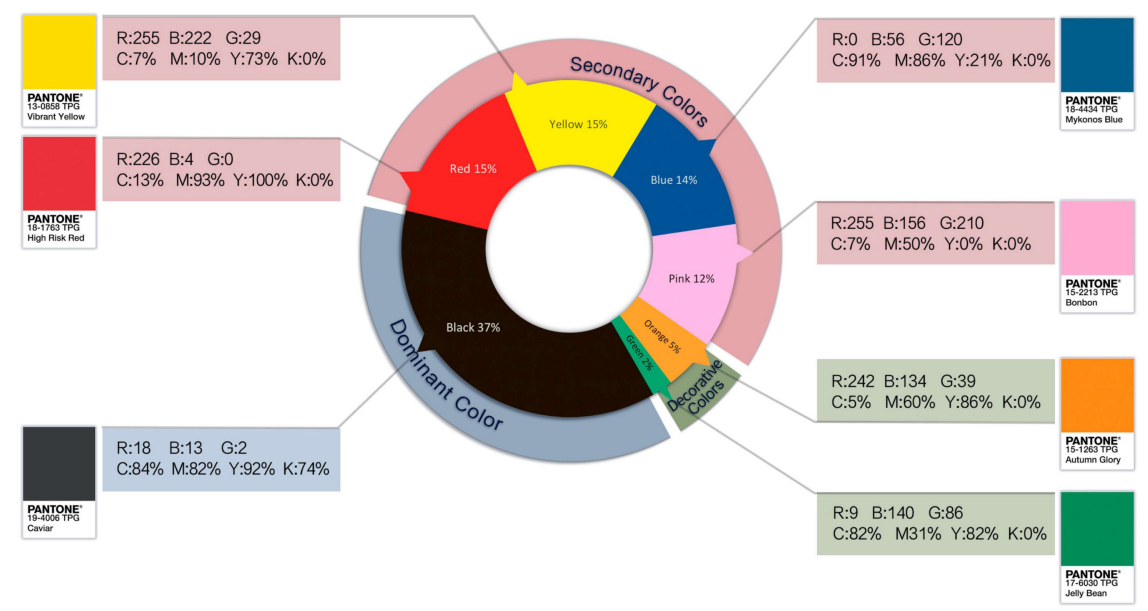

Figure 3. Illustration of the color scheme of Yi women's costume.

References for the color scheme of female costume:

\subsubsection{Color Images}

Traditional $(M=1.76)$, Complex $(M=1.83)$, Festive $(M=1.88)$, Passionate $(M=1.89)$, Heavy $(M=1.90)$, Hard $(M=2.07)$, Unique $(M=2.30)$ and Splendid $(M=2.74)$

\subsubsection{Instructions for Color Scheme}

1. Color area ratio: dominant color, black $37 \%$. Secondary colors, red, $15 \%$; yellow, $15 \%$; blue, $14 \%$; and pink, $12 \%$. Decorative colors: orange, $5 \%$ and green, $2 \%$.

2. Principles of color scheme: large areas of color black; areas of blue; yellow, red and pink stripes for emphasis; green, orange lines and lines in other decorative colors repeatedly embellished on the edge.

In order to build samples of the color scheme of Yi women's costume, 4 designers with more than 5 years of design experience are invited to conduct a focus group discussion. Before starting 
the discussion, they receive the illustration of color scheme and references for the color scheme of Yi women's costume, based on which each of them draws a $10 \mathrm{~cm} \times 10 \mathrm{~cm}$ sample of color scheme using CorelDREW/AI within 30 min. Finally, each designer comes up with 4 samples of color scheme, a total of 16 samples. After discussion, the designers are asked to vote and exchange opinions and delete similar ones and those that are not in line with the principles of color scheme. Thus, 8 designs with patterns of strong characteristics of Yi women's costume (Figure 4) are selected as color scheme samples.

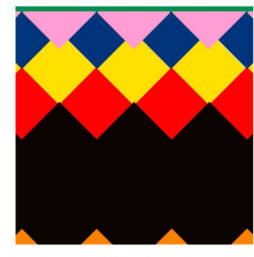

YF-1

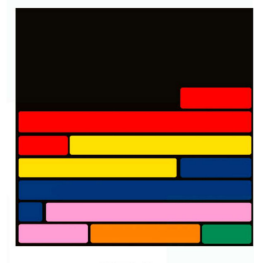

YF-5

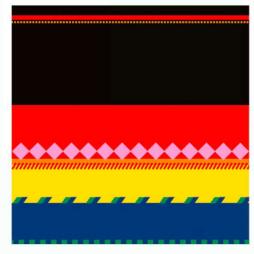

YF-2

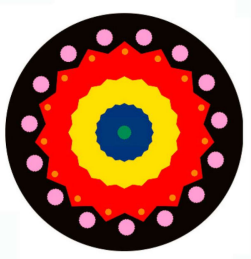

YF-6

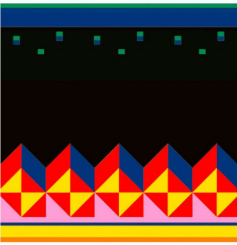

YF-3

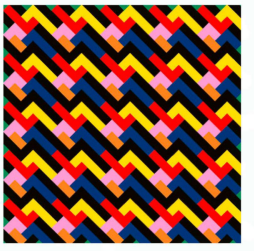

YF-7

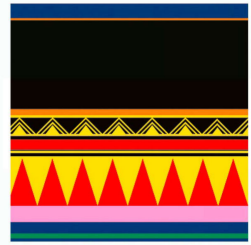

YF-4

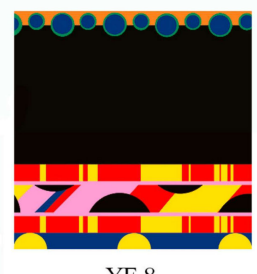

YF-8

Figure 4. Color scheme samples of Yi women's costume.

\subsection{Verification on Color Scheme Samples}

Through combining 8 samples of the color scheme of Yi women's costume with the adjectives of color images, a questionnaire based on Likert five-point scale is made. A total of 92 subjects with design-related background for over 3 years are invited to finish the questionnaire, and 89 valid questionnaires are collected in order to understand whether these 8 design samples convey the same color images as real Yi women's costume.

The statistical method used for verification in this study is One-Sample Kolmogorov-Smirnov Test [40]. If the significance $p$ value in the test form is higher than 0.05 , it means that the participants tend to be "neutral" with no bias. If the significance $p$ value is less than 0.05 and the absolute value of the positive most extreme difference is higher than that of the absolute value of the negative most extreme difference, it indicates that participants tend to "disagree" that the picture conforms to the color images of traditional Yi women's costume. If the significance $p$ value is less than 0.05 and the absolute value of the negative most Extreme difference is higher than that of the absolute value of the positive most Extreme difference, it indicates that participants tend to "agree" that the picture conforms to the color images of traditional Yi women's costume.

Evaluation on color scheme samples of female costume:

Yi women's costume is featured with 8 types of color images including Traditional, Splendid, festive, Complex, Heavy, Passionate, Unique and Hard. According to the statistics in Table 4, the significant $p$ values are all less than 0.05 with the absolute value of the negative most Extreme difference being higher than that of the absolute value of the positive most Extreme difference, indicating that participants tend to "agree" that the graphs in samples conform to the word list that describes the traditional female costume of Yi people. All the 8 sets of adjectives in YF-1 to YF-8 are of significance, and the participants, on the whole, tend to agree that the color images of 8 samples are consistent with that of the original pictures of Yi women's costume. 
Table 4. Verification on color scheme samples of Yi women's costume.

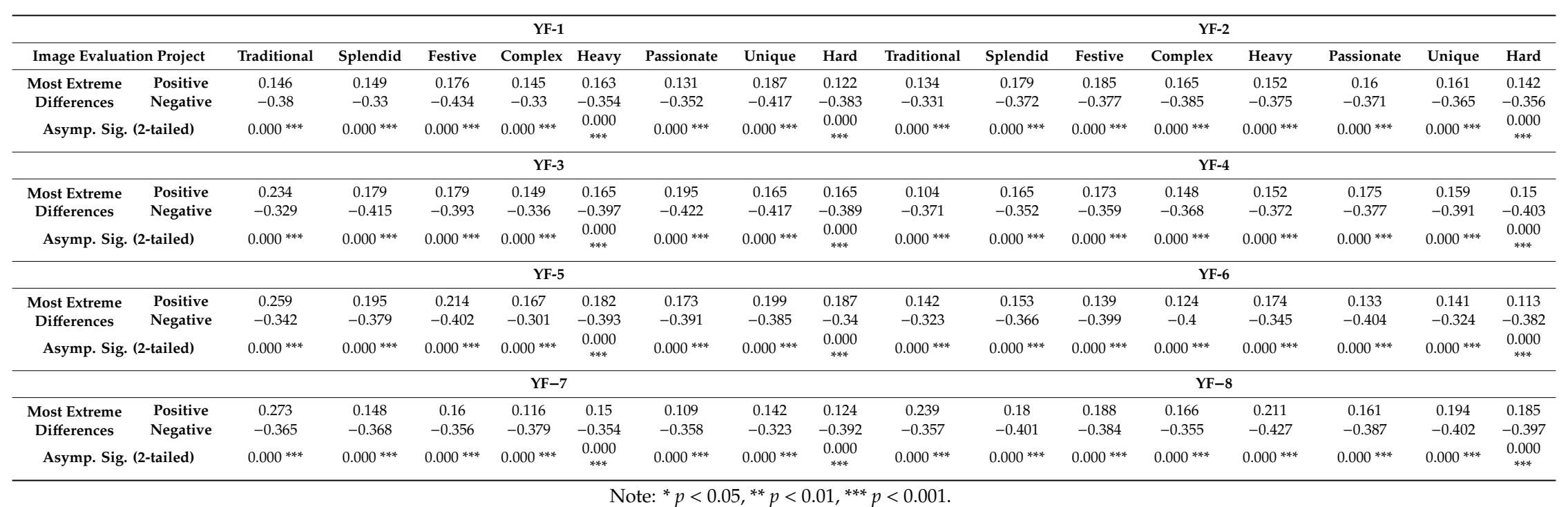


Through statistical verification and evaluation, the results show that the color images of the color scheme samples are consistent with that of the original costume pictures, which means the subjects' perception of color images is similar to that of the original costume pictures and the color scheme samples are reliable and able to represent common female costume of Yi people and serve as a reference for the design and development of Yi-related products in the future.

\section{Conclusions}

In order to systematically analyze regional cultural colors, this study first clarifies the definition of the traditional costume of the Yi women in Liangshan, color and culture, and color images and the characteristics of research samples through literature review. Secondly, the color values of different colors on Yi women's costume are found out and recorded through Pantone Color Guide, and ImageJ is resorted to in order to calculate the area ration of each color and analyze the color distribution principles of sample costume. Moreover, the color images of Yi women's costume are discussed so as to sort out its unique color characteristics, and samples of color scheme are established and verified through focus group discussion in order to analyze regional cultural colors.

Based on the geography of color, this study takes Liangshan Yi women's costume as an example and proposes a set of recording methods for regional cultural colors. If researchers in the future would like to establish color scheme systems related to various cultures and ethnic groups as in this study, they may conduct color sorting according to the cultural color analysis method proposed in this study. The steps are as follows:

1. Understand color characteristics. Through knowing and understanding culture, analyze the color samples in a scientific way, define the standard color of the culture, and summarize the color attributes and characteristics unique to the culture.

2. Analysis of color images. Culture of different regions has its own characteristics and symbols. Through the psychological experiment of images, understand the perception that the colors of a certain culture convey to people and make it the basis for criteria of color scheme.

3. Establish color scheme samples. Summarize and organize the records of color, ask designers to assist in establishing color scheme samples and evaluate the effectiveness of such samples.

4. Principles of color scheme. Establish comprehensive color scheme principles as a basis for promoting and advertising regional cultural colors.

\section{Research Limitations:}

1. The colors of costume usually change with the times, mainly because the materials obtained are different due to environmental reasons. Therefore, the colors used by costume makers can be slightly different. In the early 1950s, most areas in Liangshan were still a slave society which was ended in 1956. After that, Liangshan entered socialist society. The samples used in this research are based on the color scheme of Liangshan Yi women's daily costume after 1956, and that before 1956 is not taken into consideration in this study.

2. According to mere exposure proposed by Robert Zajonc in 1968, the more common a stimulus is, whether it is a figure or a human face, the more people will like it, meaning the frequency of the stimulus is positively correlated with the degree of people's preference. Therefore, this study only discusses the colors on the front side of the costume without taking headwear, necklaces and other accessories into consideration [41].

This study employs a relatively systematic approach to effectively record and preserve the colors on Liangshan Yi women's costume and convey traditional elements in modern language, allowing designers to follow the directions and principles when designing Yi-related cultural creative products. This kind of systematic approach to preserve colors helps connect the traditional culture of Liangshan Yi with modern culture and can be used as a reference for the development and designing of Yi-related products in the future. Furthermore, in addition to the establishment of principles of the 
color scheme of Liangshan $\mathrm{Yi}$, the research process of this study is also applicable to the establishment of color scheme principles for other ethnic groups in the future. Through systematic analysis of regional cultural colors, the system of Chinese regional cultural color scheme can be established and preserved and serve as a reference for designers to design products related to ethical culture, which is of great significance in the preservation and promotion of intangible culture.

Author Contributions: Z.J. and M.L. collected and organized data; Z.J. wrote the manuscript with the supervision of W.-H.H. and Z.J. acted as a corresponding author. All authors have read and agreed to the published version of the manuscript.

Funding: This research received no external funding.

Conflicts of Interest: The authors declare no conflict of interest.

\section{References}

1. UNESCO. Convention on the Protection and Promotion of the Diversity of Cultural Expressions. Available online: https://en.unesco.org/creativity/convention/texts (accessed on 10 April 2018).

2. Guangli, W. Research on the Art of Patterns on Yi Nationality's Costume; Kunming University of Science and Technology: Kunming, China, 2007.

3. Ning, S.; Qinchuan, Z. On the Integration of National Costume Elements and Modern Costume Design. In Proceedings of the International Conference on Information Technology and Career Education, Beijing, China, 29-30 September 2013; p. 02013.

4. Xiao-ran, F. Influence of National Costume on Fashion. Chem. Fiber Text. Technol. 2012, 2, 11.

5. Bakieva, O.; Popova, O. Features of color mentality of the indigenous small nationalities of the Arctic (on the example of the analysis of the traditional Khanty people costume). In Proceedings of the IOP Conference Series: Earth and Environmental Science, Saint Petersburg, Russia, 17-18 April 2019; p. 012157.

6. Juan, L. Analyze Traditional Chinese Border and National Costume Design. Tianjin Text. Sci. Technol. 2006, 3,10 .

7. Lenclos, J.-P.; Lenclos, D. Colors of the World: The Geography of Color; WW Norton \& Company: New York, NY, USA, 2004.

8. Singh, S. Impact of color on marketing. Manag. Decis. 2006, 44, 783-789. [CrossRef]

9. Fairchild, M.D. Color Appearance Models; John Wiley \& Sons, Inc.: Hoboken, NJ, USA, 2013.

10. Tsuneo, K. Principles of Color; Rikoh Tosho: Tokyo, Japan, 1969.

11. Jiang, Q.; Chen, L.-C.; Zhang, J. Perception and Preference Analysis of Fashion Colors: Solid Color Shirts. Sustainability 2019, 11, 2405. [CrossRef]

12. Hillenbrand, P.; Alcauter, S.; Cervantes, J.; Barrios, F. Better branding: Brand names can influence consumer choice. J. Prod. Brand Manag. 2013, 22, 300-308. [CrossRef]

13. Choi, H.H.; Lim, S.A.; HeeKim, J. Promotional Video of Editing Techniques Utilizing Color and Brand Balance. Int. J. Softw. Eng. Appl. 2014, 8, 149-158.

14. Miller-Spillman, K.A.; Kimberly, A.; Reilly, A. The Meanings of Dress; Fairchild Books: New York, NY, USA, 2019.

15. Yang, Y. On Color Signs of Yi Ethnic Group in Liangshan. Beauty Times 2015, 7, 135-136. [CrossRef]

16. Zhong, S.; Zhou, W. The Yi Nationality's Costumes and Ornaments in China; Yunnan Fine Arts Publishing House: Kunming, China, 2006.

17. Zhang, L. On Dominant Elements of Yi Nationality's Costume Patterns. J. Southwest Univ. Natl. (Humanit. Soc. Sci.) 2014, 7, 45-48. [CrossRef]

18. Wu, H. The Costume of the Yi Women in Liangshan. Art Panor. 2007, 10, 18-19. [CrossRef]

19. Lamb, T.; Bourriau, J. Colour: Art and Science; Cambridge University Press: Cambridge, UK, 1995; Volume 7.

20. McKellar, P. The Investigation of Mental Images; Penguin Books: London, UK, 1965.

21. Osgood, C.E.; Suci, G.J.; Tannenbaum, P.H. The Measurement of Meaning; University of Illinois Press: Champaign, IL, USA, 1957.

22. Kobayashi, S. The aim and method of the color image scale. Color Res. Appl. 1981, 6, 93-107. [CrossRef]

23. Garth, T.R. The Color Preferences of Five Hundred and Fifty-Nine Full-Blood Indians. J. Exp. Psychol. 1922, 5, 392. [CrossRef] 
24. Choungourian, A. Color preferences and cultural variation. Percept. Mot. Ski. 1968, 26, 1203-1206. [CrossRef]

25. Ou, L.C.; Ronnier Luo, M.; Sun, P.L.; Hu, N.C.; Chen, H.S.; Guan, S.S.; Woodcock, A.; Caivano, J.L.; Huertas, R.; Treméau, A. A cross-cultural comparison of colour emotion for two-colour combinations. Color Res. Appl. 2012, 37, 23-43. [CrossRef]

26. Ou, L.C.; Luo, M.R.; Sun, P.L.; Hu, N.C.; Chen, H.S. Age effects on colour emotion, preference, and harmony. Color Res. Appl. 2012, 37, 92-105. [CrossRef]

27. Hurlbert, A.C.; Ling, Y. Biological components of sex differences in color preference. Curr. Biol. 2007, 17, R623-R625. [CrossRef]

28. Schloss, K.B.; Poggesi, R.M.; Palmer, S.E. Effects of university affiliation and "school spirit" on color preferences: Berkeley versus Stanford. Psychon. Bull. Rev. 2011, 18, 498-504. [CrossRef]

29. Ou, L.C.; Luo, M.R.; Woodcock, A.; Wright, A. A study of colour emotion and colour preference. Part I: Colour emotions for single colours. Color Res. Appl. 2004, 29, 232-240. [CrossRef]

30. Shigenobu, K. Psychology on Pattern Formation; Kabushiki Kaisha Daviddosha: Tokyo, Japan, 2002.

31. Kobayashi, S. Color Image Scale. 2009. Available online: http://www.ncd-ri.co.jp/english/main_0104.html (accessed on 20 May 2019).

32. Hsu, M.Y.; Ou, L.C.; Guan, S.S. Colour preference for Taiwanese floral pattern fabrics. Color Res. Appl. 2016, 41, 43-55. [CrossRef]

33. Liu, J.; Lughofer, E.; Zeng, X. Could linear model bridge the gap between low-level statistical features and aesthetic emotions of visual textures? Neurocomputing 2015, 168, 947-960. [CrossRef]

34. Xin, J.H.; Cheng, K.; Taylor, G.; Sato, T.; Hansuebsai, A. Cross-regional comparison of colour emotions Part I: Quantitative analysis. Color Res. Appl. 2004, 29, 451-457. [CrossRef]

35. Sato, T.K.K.; Hoshino, H.; Nakamura, T. Quantitative evaluation and categorising of human emotion induced by colour. Adv. Colour Sci. Technol. 2000, 3, 53-59.

36. Thumfart, S.; Jacobs, R.H.; Lughofer, E.; Eitzinger, C.; Cornelissen, F.W.; Groissboeck, W.; Richter, R. Modeling human aesthetic perception of visual textures. ACM Trans. Appl. Percept. (TAP) 2008, 8, 1-29. [CrossRef]

37. Lee, W.Y.; Pai, S.Y. The affective feelings of colored typefaces. Color Res. Appl. 2012, 37, 367-374. [CrossRef]

38. Ou, L.C.; Luo, M.R.; Woodcock, A.; Wright, A. A study of colour emotion and colour preference. part II: Colour emotions for two-colour combinations. Color Res. Appl. 2004, 29, 292-298. [CrossRef]

39. Wu, M.; Tu, J. SPSS \& The Application and Analysis of Statistics; Wu-Nan Book: Taipei, Taiwan, 2016.

40. Justel, A.; Peña, D.; Zamar, R. A multivariate Kolmogorov-Smirnov test of goodness of fit. Stat. Probab. Lett. 1997, 35, 251-259. [CrossRef]

41. Zajonc, R.B. Mere exposure: A gateway to the subliminal. Curr. Dir. Psychol. Sci. 2001, 10, $224-228$. [CrossRef]

Publisher's Note: MDPI stays neutral with regard to jurisdictional claims in published maps and institutional affiliations.

(C) 2020 by the authors. Licensee MDPI, Basel, Switzerland. This article is an open access article distributed under the terms and conditions of the Creative Commons Attribution (CC BY) license (http://creativecommons.org/licenses/by/4.0/). 